\title{
A numerical study of three- dimensional natural convection in a differentially heated cubical enclosure
}

\author{
H. S. Lee / J. H. Jung \\ : Department of Naval Architecture and Ocean Engineering \\ Pusan National University \\ San 30, Jangjeon 2-Dong, Gumjeong-Gu \\ Busan 609-735, Korea \\ pi@pusan.ac.kr / vof@pusan.ac.kr
}

\author{
H. S. Yoon \\ : Global Core Research Center for Ships and Offshore Plants \\ Pusan National University \\ San 30, Jangjeon 2-Dong, Gumjeong-Gu \\ Busan 609-735, Korea \\ lesmodel@pusan.ac.kr
}

\begin{abstract}
A high-resolution, finite difference numerical study is reported on three-dimensional steady-state natural convection of air, for two Rayleigh numbers, in a cubical enclosure, which is heated differentially at one side walls. The temperature of the wall is $T_{C}$ except for the right vertical wall, in which is $T_{H}$. The details of the three-dimensional flow and thermal characteristics are described.
\end{abstract}

Keywords - three dimension; steady-state; natural convection; cubical enclosure;

\section{INTRODUCTION}

Natural convection flow analysis in enclosure has many thermal engineering applications, such as cooling of electronic devices, energy storage systems and compartment fires. In the present paper, a numerical study is reported on steady-state three-dimensional natural convection in an air-filled cubical enclosure, which is heated differentially at one side walls. As shown in Fig. 1, the temperature of the wall is $T_{C}$ except for the right vertical wall (at $\mathrm{x}=\mathrm{L}_{0}$ ), in which is $\mathrm{T}_{\mathrm{H}}$. The present geometry and the boundary conditions are mathematically well posed and they provide a basic model for relevant thermal engineering systems.

Two-dimensional numerical analyses for a square cavity filled with air have been carried out in the past over a wide range of Rayleigh numbers. Results for $10^{3} \leq \mathrm{Ra} \leq 10^{6}$ were presented in Markatos and Pericleous [1]. The laminar flow regime was assumed up to the Rayleigh number of $10^{6}$, and for higher Rayleigh numbers, the $\mathrm{k}-\varepsilon$ turbulence model was used. For $10^{3} \leq \mathrm{Ra} \leq 10^{6}$ and a Boussinesq fluid of $\operatorname{Pr}=0.71$, a set of benchmark solutions has been suggested by de Vahl Davis [2]. By resorting to systematic grid refinement practice and by concurrent use of the Richardson extrapolation to obtain grid independent data, these solutions were claimed to be within accuracy of $1 \%$.

In order to simulate practical situations, three-dimensional flow calculations are highly desirable. Three-dimensional laminar flows have been studied for enclosures of the depth aspect ratio, $A_{z}$, varying from 2 to $4[3,4]$. Gross features observed in the enclosures revealed highly three-dimensional structures of the flow. The enclosures with $A_{z}=1$ and 2 were considered in Lankhorst and Hoogendoorn [5] ; they were computed for three Rayleigh numbers: $\mathrm{Ra}=10^{6}, 4 \times 10^{8}$ and $10^{10}$. In the last two cases, the $k-\varepsilon$ turbulence model was employed. However, it is emphasized that these previous calculations were executed by using relatively coarse finite difference meshes, of up to $45 \times 45 \times 20$.

The present investigation is implemented on a much finer mesh system with a view toward delineating steady-state threedimensional structures of the fields with sufficient resolution. The numerical resolution in the present three-dimensional calculations is comparable to the highest one among the preceding two-dimensional results [2]. The Rayleigh number ranges from $10^{3}$ to $10^{6}$. The Prandtl number of the fluid is held fixed at 0.71 . Comprehensive details of the flow and temperature fields are presented by displaying elaborate three-dimensional color graphics and illustrative field quantities. By inspecting these results of the realistic three-dimensional calculations, the validity of the prior two-dimensional results can be also assessed.

The majority of the past experimental works have studied high aspect ratio enclosures, but relatively little research endeavor has been devoted to the cases of small aspect ratio cavities [6-11]. In most of these experimental investigations, care was taken to justify the two-dimensional approximation. Depth aspect ratios, $A_{z}$, greater than 5 were adopted in refs.[6-8] in an effort to minimize the end effect of the finite enclosure. By using a Mach -Zehnder interferometer technique. Bajorek and Lloyd [6] visualized the temperature field in square enclosures, with and without partitions, for $1.7 \times 10^{5} \leq \mathrm{Ra} \leq 3 \times 10^{6}$. The media considered were air and carbon dioxide gas. Laser Doppler velocity measurements in the identical geometry were conducted in ref. [7] for air at Rayleigh numbers of $10^{5}$ and $10^{6}$. The same measurement techniques were utilized by Krane and Jessee [8], who acquired both velocity and temperature distributions at $\mathrm{Ra}=1.89 \times 10^{5}$ and for air.

In actual experiments, it is nearly impossible to perfectly insulate the surfaces, especially when air is chosen as the medium. Heat transfer from the supposedly adiabatic walls is unavoidable. The effects of conducting horizontal walls have been 


\section{NOMENCLATURE}

A aspect ratio, (enclosure height/width)

$\mathrm{A}_{\mathrm{z}}$ depth aspect ratio, (enclosure depth/width)

$c_{p} \quad$ specific heat at constant pressure

Fr Froude number, $u_{0}{ }^{2} / g * L_{0}$

$g$ gravitational acceleration :

$k \quad$ thermal conductivity

$L_{0} \quad$ reference length (enclosure height)

$p \quad$ pressure

$p_{0} \quad$ reference pressure (hydrostatic pressure)

$\operatorname{Pr} \quad$ Prandtl number. $c_{p}{ }^{*} / k^{*}$

$\mathrm{Ra}$ Rayleigh number,

$$
g^{*} \beta^{*} c_{p}{ }^{*} \rho^{2} L_{0}^{3}\left(T_{\mathrm{H}}-T_{\mathrm{C}}\right) / \mu^{*} k^{*}
$$

Re Reynolds number, $\rho^{*} u_{0} L_{0} / \mu^{*}$

$\mathrm{t}$ time

$\mathrm{T}$ temperature

$\begin{array}{ll}T_{0} & \text { reference temperature. }(7 ;+\mathrm{r}-,,) \sim 2 \\ T_{\mathrm{C}}, T_{\mathrm{H}} & \text { cooled and heated side wall } \\ & \text { temperatures } \\ u_{0} & \text { reference velocity, }\left[g^{*} \beta^{*} L_{0} *\left(T_{\mathrm{H}}-T_{\mathrm{C}}\right)\right]^{1 / 2} \\ u, v, w & \text { velocity components in the and } x-, y \text { - and } \\ & z \text {-directions }\end{array}$

$x, y, z \quad$ Cartesian coordinates

Greek symbols

$\begin{array}{ll}\beta & \text { thermal expansion coefficient } \\ \delta & \text { overheat ratio, }\left(T_{\mathrm{H}}-T_{\mathrm{C}}\right) / T_{0} \\ \mu & \text { viscosity } \\ \rho & \text { density. }\end{array}$

Superscript

* dimensional quantities. of considerable interest. The behavior of steady periodic oscillations in the flow field was the subject of the experimental work by Briggs and Jones [9] with a cubical enclosure having a linear temperature profile on the horizontal walls. Bohn et al. [10] constructed a water-tilled cube with isothermal walls, and the combined effects of the side and bottom heating on the heat transfer rate for water were studied.

A recent investigation [11] was conducted in a differentially heated cubical enclosure (the geometry of present interest) for a high Prandtl number fluid $(\mathrm{Pr}=6000)$. Visualization experiments with liquid crystal tracers suspended in mixtures of glycerol and water were made for $10^{4} \leq \mathrm{Ra} \leq 2 \times 10^{7}$ : the Rayleigh number range overlaps that of the present analysis. The streamline patterns were compared with the parallel numerical results executed on a finite difference mesh system of 31'. Global features were in agreement, although the changes in the structure of the streamlines occurred at different Rayleigh numbers between the measurements and the computations.

The primary impetus of the present work is to portray the details of the three-dimensional local characteristics of the fields. Given the fact that any realistic laboratory experiment is threedimensional in nature the two-dimensional numerical simulations to date have been unable to fully describe the salient features associated with the real systems. As mentioned earlier, the existing three-dimensional numerical simulations are still in a rudimentary stage. The existing numerical studies have, by and large, suffered from insufficient resolution : the prominent characteristics of complicated three-dimensional situations have not been described in sufficient depth. In particular, at high Rayleigh numbers, greatly enhanced numerical capabilities are essential to depict the significant dynamic features in thin boundary layers.

In the present study, a massive utilization of the state-ofthe-art computational resources has been made. The vastly expanded hardware capabilities together with such advanced computational techniques, will enable us to implement the three-dimensional numerical simulations of the flow and heat transfer properties in the enclosure. These numerical results will allow proper verification of the experimental observations. It is also noteworthy that, by cross-checking the results, the extent of the applicability of the earlier two-dimensional results to actual three-dimensional systems will be illuminated.

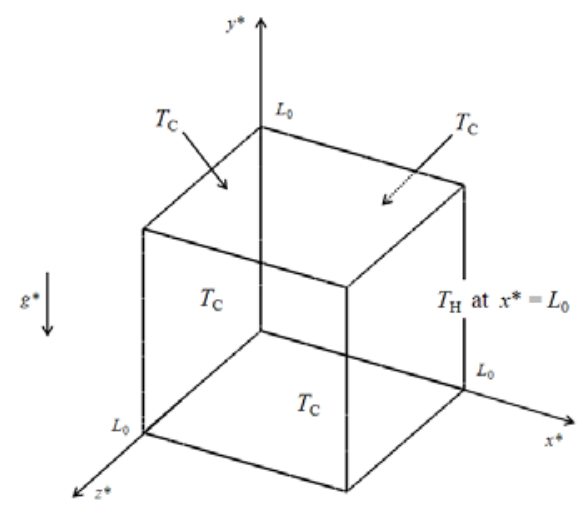

Fig. 1. The flow geometry in a cube of length $L_{0}$. The solid walls temperature is $\mathrm{T}_{\mathrm{C}}$, except for $x^{*}=0$ and $L_{0}$ as noted. 


\section{MATHEMATICAL MODEL}

The flow field is described by the incompressible NavierStokes equations and the energy equation. The Boussinesq approximation is invoked for the fluid properties. The nondimensionalized form of the governing equations can be expressed in tensor notation as

$$
\begin{aligned}
& \frac{\partial u_{j}}{\partial x_{j}}=0 \\
& \frac{\partial u_{i}}{\partial t}+\frac{\partial}{\partial x_{j}}\left(u_{j} u_{i}\right)=-\frac{\partial p}{\partial x_{i}}+\frac{1}{\operatorname{Re}} \frac{\partial^{2} u_{i}}{\partial x_{j} \partial x_{j}}+\delta_{i 2} \frac{T-1}{F r} \\
& \frac{\partial T}{\partial t}+\frac{\partial}{\partial x_{j}}\left(u_{j} T\right)=\frac{1}{\operatorname{RePr}} \frac{\partial^{2} T}{\partial x_{j} \partial x_{j}}
\end{aligned}
$$

where 6 , is the Kronecker delta $\left(\delta_{\mathrm{ij}}=1\right.$ if $i=j$, and $\delta_{\mathrm{ij}}=0$ otherwise). The viscous dissipation and the pressure work terms are neglected in the energy equation.

The physical quantities are non-dimensionalized in the following manner :

$$
\begin{gathered}
(x, y, z)=\left(x^{*}, y^{*}, z^{*}\right) / L_{0}, \quad(u, v, w)=\left(u^{*}, v^{*}, w^{*}\right) / u_{0} \\
t=t^{*} u_{0} / L_{0}, \quad p=\left(p^{*}-p_{0}\right) / \rho^{*} u_{0}{ }^{2}, \quad T=T^{*} / T_{0}
\end{gathered}
$$

where an asterisk $(*)$ denotes dimensional values. The reference scales for length, velocity, pressure and temperature are the enclosure height $\left(L_{0}\right)$, the convective velocity $\left(\mathrm{u}_{0}=\left[g^{*} \beta^{*}\right.\right.$ $\left.\left.L_{0}\left(\mathrm{~T}_{\mathrm{H}}-\mathrm{T}_{\mathrm{C}}\right)\right]^{1 / 2}\right)$, the hydrostatic pressure $\left(p_{0}\right)$ and the film temperature $\left(\mathrm{T}_{0}=\left(\mathrm{T}_{\mathrm{C}}+\mathrm{T}_{\mathrm{H}}\right) / 2\right)$, respectively. In the present nondimensionalization, the Rayleigh, Prandtl and Reynolds numbers are related as $R a=R e^{2} P r$. The Prandtl number is held fixed at 0.71 for air in the present.

The boundary conditions are

$$
\begin{gathered}
u=v=w=0 \text { on all the walls } \\
\mathrm{T}=(2-\delta) / 2 \text { at } x=0, \mathrm{~T}=(2+\delta) / 2 \text { at } x=1, \\
\text { and } \partial \mathrm{T} / \partial \mathrm{n}=0 \text { at } y=0,1 \text { and } z=0,1
\end{gathered}
$$

where $n$ indicates the coordinate normal to the surface. The overheat ratio, $\mathrm{S}$, is set equal to 0.1 in the present analysis.

\section{SOLUTION METHOD}

A discretized form of the governing equations (l)-(3) is secured by a control-volume based finite difference procedure. Numerical solutions are acquired by an iterative method, together with the pressure correction algorithm, SIMPLE [12]. The present technique employs the Strongly Implicit Scheme (SIP) [13] to accelerate convergence characteristics of the solutions. SIP is applied to the planes of constant $z$ in order to determine simultaneously the dependent variables in the $x$ - and $y$ directions on each plane.

The convection terms in the momentum equation (2) are treated by the QUICK methodology [14, 15]. The QUICK scheme involves a third-order accurate upwind differencing, which possesses the stability of the first-order upwind formula and is free from substantial numerical diffusion experienced with the usual first-order techniques. In the present numerical procedure, a non-uniform grid version is adopted. The convection terms in the energy equation (3) are dealt with by a hybrid scheme [12].

The entire enclosure constitutes the full computational domain. The number of grid points for computations is $62 \times 62 \times$ 62. Variable grid spacing is introduced to resolve steep gradients of the velocity and the temperature near the walls.

Convergence of computations is declared when the following convergence criterion is satisfied :

$$
\frac{\left|\phi_{n}-\phi_{n-1}\right|}{\left|\phi_{n}\right|_{\text {maximum }}} \leq 10^{-4} \text { for all } \phi
$$

where $\phi$ represents any dependent variable, and $n$ refers to the value of $\$ \mathrm{~J}$ at the nth iteration level.

At each Rayleigh number, the converged solution for a lower Rayleigh number is used as the initial guess. In actual computations, transient calculations are conducted by an implicit method to generate steady-state solutions.

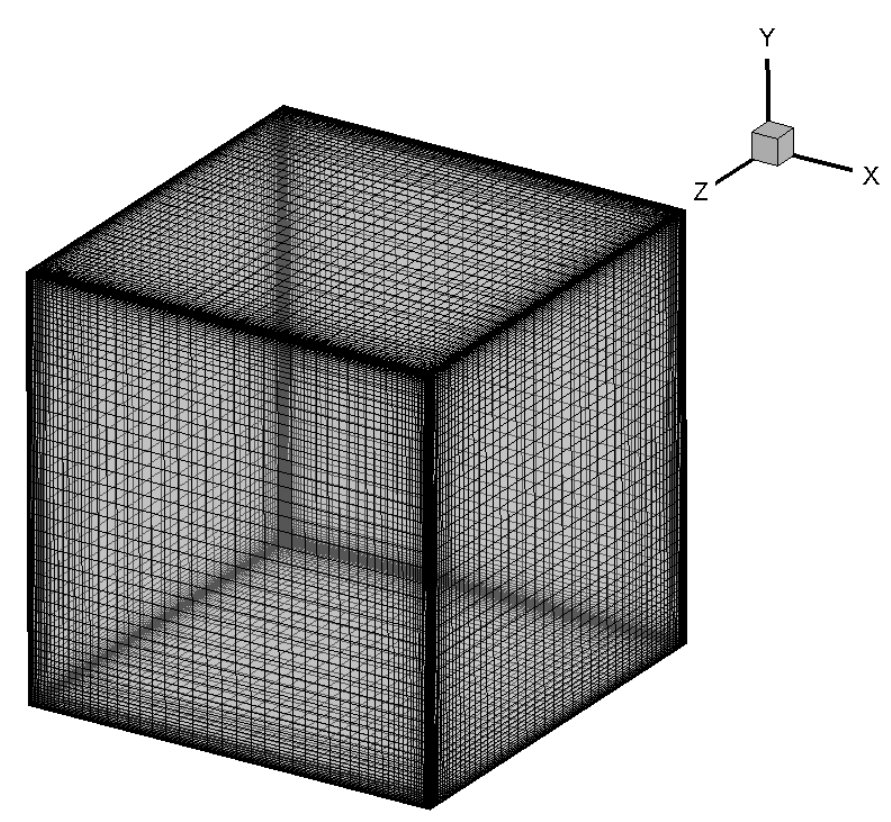

Fig. 2. Grid distribution of computational domain

\section{RESUlTS}

The global field characteristics arc cxamincd by viewing comprehensive three-dimensional contours of the temperature and Bow fields. Results for three Rayleigh numbers are inspected in detail in the following three subsections : $\mathrm{Ra}=10^{3}$, $10^{4}$ and $10^{5}$. The former cast exemplifies a flow field in which the relative importance of convection is generally less significant. However, the latter case is representative of the flow structure in which convection is intense such that distinct boundary layers are discernible near the isothermal solid walls. 


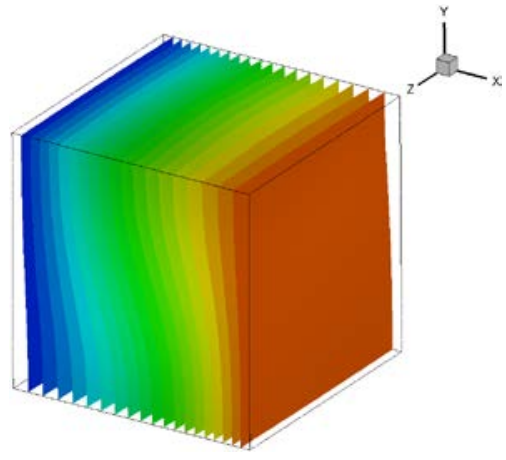

(a)

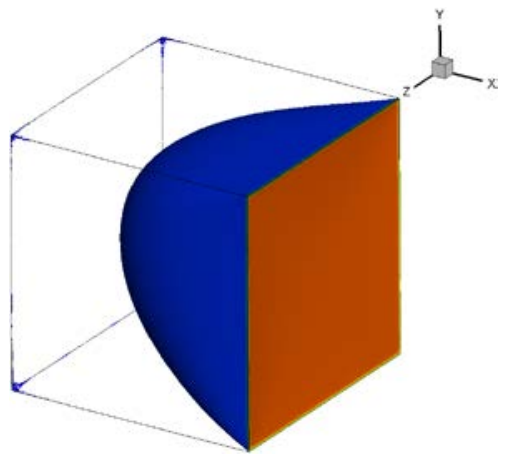

(b)

Fig. 3. The temperature field at $\mathrm{Ra}=10^{3}$ : (a) Fusegi et al.[16] ; (b) present results

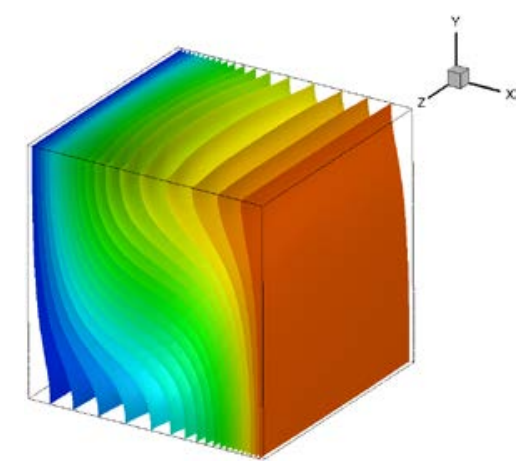

(a)

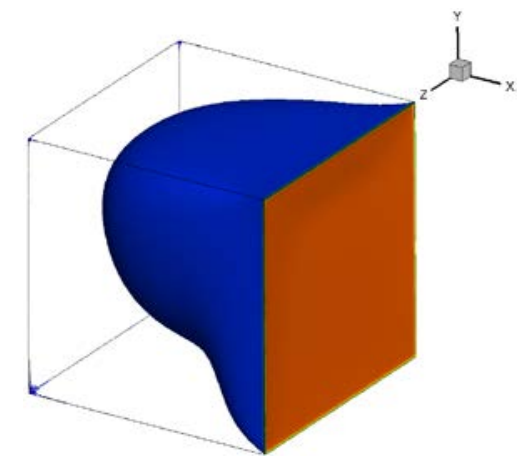

(b)

Fig. 4. The temperature field at $\mathrm{Ra}=10^{4}$ : (a) Fusegi et al. ; (b) present results

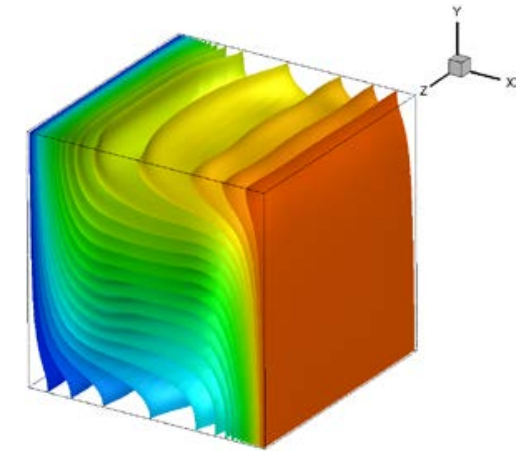

(a)

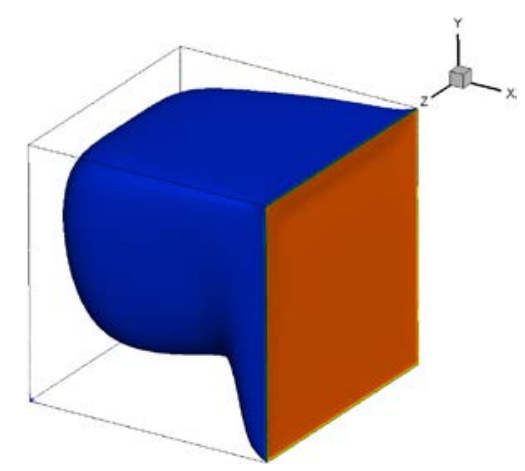

(b)

Fig. 5. The temperature field at $\mathrm{Ra}=10^{5}$ : (a) Fusegi et al. ; (b) present results

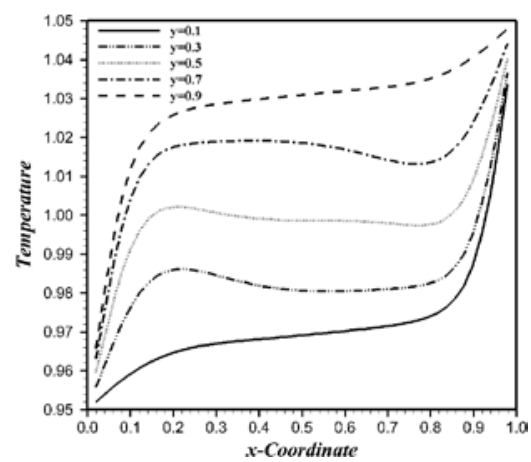

(a)

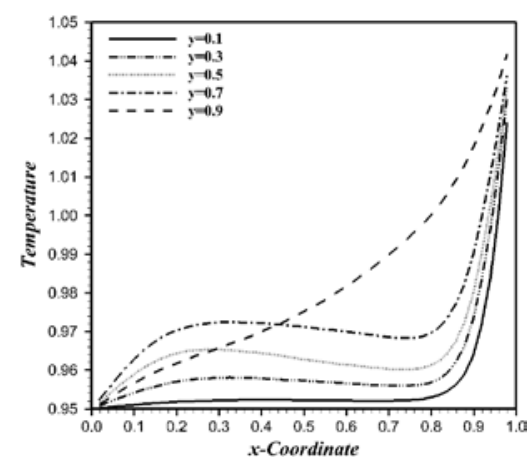

(b)

Fig. 6. Comparison of the temperature profiles in the symmetry plane at $\mathrm{z}=0.5\left(R a=10^{5}\right)$ : (a) Fusegi et al. ; (b) present results 


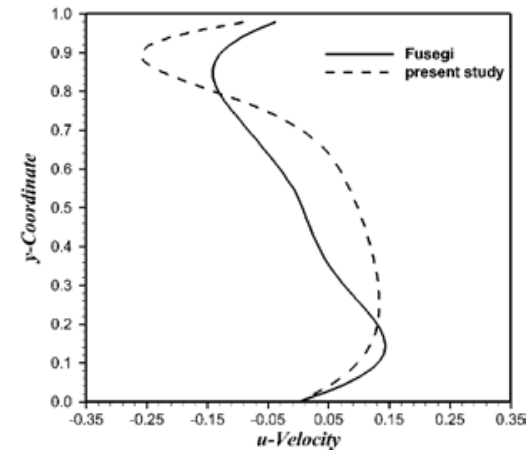

(a)

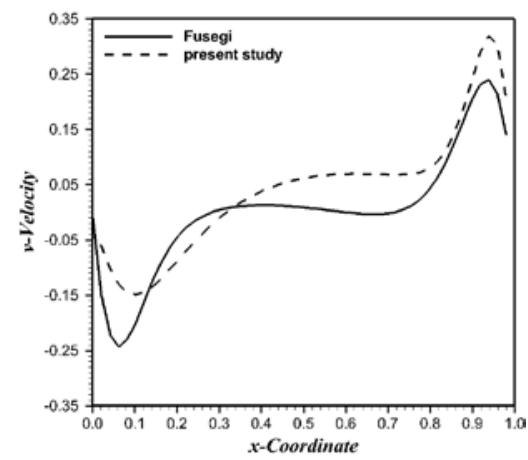

(b)

Fig. 7. Comparison of the velocity profiles in the symmetry plane at $\mathrm{z}=0.5\left(R a=10^{5}\right)$ : (a) at $x=0.5$; (b) at $y=0.5$

\section{REFERENCE}

[1] N.C. Markatos and K. A. Pericleous, "Laminar and turbulent natural convection in an enclosed cavity”, Int. J. Heat Mass Transfer 27, 755772, 1984.

[2] G. de Vahl Davis, "Natural convection of air in a square cavity: a bench mark numerical solution”, Int. J. Numer. Meth. Fluids 3, 249-264,1983.

[3] G. D. Mallinson and G. de Vahl Davis, "Three-dimensional natural convection in a box : a numerical study”, J. Fluid Mech. 83, 1-31,1977.

[4] T. S. Lee, G. H. Son and J. S. Lee, "Numerical predictions of threedimensional natural convection in a box", Proc. 1st KSME-JSME Thermal and Fluids Engng Conf., Vol. 2, pp. 278-283,1988.

[5] A. M. Lankhorst and C. J. Hoogendoorn, "Three-dimensional numerical calculations of high Rayleigh number natural convective flows in enclosed cavities", Proc. 1988 Natn. Heat Transfer Conf., ASME HTD-96, Vol. 3, pp.463-470,1988.. .

[6] S. M. Bajorek and J. R. Lloyd, Experimental investigation of natural convection in partitioned enclosures, J. Heat Transfer 104, pp. 527-532, 1982.

[7] S. M. Bilski, J. R. Lloyd and K. T. Yang, "An experimental investigation of the laminar natural convection velocity in square and partitioned enclosures”, Proc. 8th Int. Heat Transfer Conf., Vol. 4, pp. 1513-1518, 1986.

[8] R. J. Krane and J. Jessee, "Some detailed field measurements for a natural convection flow in a vertical square enclosure", Proc. 1st ASMEJSME Thermal Engng Joint Conf., Vol. 1, pp. 323-329, 1983.

[9] D. G. Briggs and D. N. Jones, "Two-dimensional periodic natural convection in a rectangular enclosure of aspect ratio one”, J. Heat Transfer 107, pp. 850-854, 1985.

[10] M. S. Bohn, A. T. Kirkpatrick and D. A. Olson, "Experimental study of three-dimensional natural convection high-Rayleigh number”, J. Heat Transfer 106, pp. 339-345, 1984.

[11] W. J. Hiller, S. Koch, T. A. Kowalewski, G. de Vahl Davis and M.Behnia, "Experimental and numerical investigations of natural con- vection in a cube with two heated side walls”, Proc. IUTAM Symp.. pp. 717-726, 1990

[12] S. V. Patankar, "Numerical Heat Transfer and Fluid Flow", Chap. 6. Hemisphere, Washington, D.C., 1980.

[13] H. L. Stone, "Iterative solution of implicit approximations of multidimensional partial differential equations", J. Numer. Analysis 5, pp. 530-558, 1968.

[14] B. P. Leonard, "A stable and accurate convection modeling procedure based on quadratic upstream interpolation”, Comput. Meth. Appl. Mech. Engng. 19, pp. 59-98, 1979.

[15] C. J. Freitas, R. L. Street, A. N. Findikakis and J. R. Koseff, "Numerical simulation of three-dimensional flow in a cavity”, Int. J. Numer. Meth. Fluids 5, pp. 561-575, 1985.

[16] T. Fusegi, J.M. Hyun, K. Kuwahara, and B. Farouk, A numerical study of three-dimensional natural convection ina differentially heated cubical enclosure, Int. J. Heat Mass Transfer 34 (6), pp. 1543-1551, 1991

\section{Creative Commons Attribution License 4.0 (Attribution 4.0 International, CC BY 4.0)}

This article is published under the terms of the Creative Commons Attribution License 4.0 https://creativecommons.org/licenses/by/4.0/deed.en_US 